\title{
Automation of the Wassermann complement-fixation test using a discrete analyser
}

\author{
J. H. GLENN* AND A. R. TURNBULL† \\ From the Departments of Chemical Pathology ${ }^{\star}$ and Bacteriology†, St. Mary's Hospital Medical School, \\ London, $W .2$
}

The increasing demands for laboratory investigations are familiar to all workers in pathology departments. These demands have been met in most cases by an increasing use of automation, particularly in haematology and biochemistry.

In serology, however, the routine use of mechanized procedures has had a limited application. This is particularly surprising in view of the relatively simple manipulations involved, most methods requiring only the addition of serum to one or more reagents followed by observation of some effect such as lysis or agglutination after a suitable period of time. Factors such as deproteinization which tend to complicate the automation of biochemical analyses do not arise in this field. Some workers (Vargues, 1964; Pugh, and Gaze, 1966) have applied the Technicon Auto-analyser to the automation of complement-fixation tests, because these constitute a major part of the routine work in serology departments, but this approach appears to have met with a limited degree of acceptance. Taylor (1969) has outlined the main shortcomings of a continuous flow system for this type of test, the chief one being the necessity for working at relatively slow sampling speeds in order to avoid sample interaction.

During the past few years, many manufacturers have produced a different type of automatic analyser based on the principle of carrying out each test in a separate reaction vessel. These are the so-called discrete analysers. This type of machine would seem to be ideally suited to the automation of serological tests since, in general, it can be programmed to carry out the addition of serum and reagents as in the manual procedure with the minimum of modification.

This paper reports the application of one of these machines, the Bioanalyst, $\star$ to the automation of the Wassermann complement-fixation test (WR).

Fig. 1 (opposite)shows a general view of a Bioanalyst. A conveyor system moves round the periphery of the machine; it consists of 120 plastic carriers, each supporting a sample cup and a $3 \times 0.5$ in test tube, mounted on a chain and driven by a synchronous motor. This moves the conveyor system forward in steps at 30 -sec. intervals. The carriers have holes into which pins may be fitted, and these, by actuating star wheel valves, start and stop the Pick-up, Dispenser, Read-out, and Auto-stop units at predetermined times. The test tubes are suspended in a heated channel which may be thermostatically controlled at temperatures up to $60^{\circ} \mathrm{C}$. Reagents and samples are added by a bank of syringes at the rear of the instrument. The volumes dispensed by these can be set by means of metal templates which have been cut to suit a particular test. The read-out transfer unit removes a portion of the contents of each tube to a colorimeter recorder unit for measurement of optical density.

\section{Method}

The automated procedure is based on the manual WR method in use at this hospital, which is briefly as follows:

\section{REAGENTS}

Antigen 'Wellcome' maltaner antigen

Complement Fresh guinea-pig serum

Sensitized cells 5 M.H.D. haemolysin 'Stayne Laboratories' in 2.5 per cent. sheep cells

COMPLEMENT is titrated manually and 1.25 M.H.D. used in each test.

In a $3 \times 0.5$ in. test tube place:

$0.2 \mathrm{ml}$. inactivated serum diluted $1: 5$ with saline

$0.2 \mathrm{ml}$. antigen

$0.2 \mathrm{ml}$. complement

Mix and incubate at $37^{\circ} \mathrm{C}$. for 1 hour.

Then add $0.2 \mathrm{ml}$. sensitized red cells. Incubate for 30 min. at $37^{\circ} \mathrm{C}$. and read. An anticomplementary control is run by adding $0.2 \mathrm{ml}$. saline in place of antigen.

For the automated method the following procedure was adopted: Load the machine with $3 \times 0.5$ in. test tubes and switch on about $30 \mathrm{~min}$. before commencing the tests. 
This allows time for the temperature to rise to $37^{\circ} \mathrm{C}$. Inactivated serum is poured into plastic specimen cups and placed on the carriers. Two known positive controls followed by two negatives are placed at the start of each batch.

Syringes are primed with reagents by operating three cycles of filling and emptying without the template in position. The template is then inserted and the motor switched on. This starts the carrier system moving. An actuating pin on the first carrier switches the various units on as it passes. The machine then carries out the following series of operations:

(1) The sample pick-up unit aspirates $0.04 \mathrm{ml}$. of inactivated serum and washes it into the corresponding reaction tube with $0.36 \mathrm{ml}$. antigen. This antigen solution is prepared by diluting 5 volumes of the antigen used in the manual method with 4 volumes of saline.

(2) The first dispenser syringe (A) adds $0.2 \mathrm{ml}$. of complement $1.5 \mathrm{~min}$. later. It has been found that the contents of the tubes are adequately mixed by the force with which the reagents are delivered. The tubes are incubated for 1 hour. At the end of this period the carriers will have made a complete circuit of the machine and the tubes will have returned to their original positions.

(3) A few minutes before the end of the incubation period dispenser (A) is rinsed with saline and primed with the sensitized red cells. These are contained in a flat-bottomed bottle and are gently agitated by a small magnetic stirrer. This dispenser is set to add $0.2 \mathrm{ml}$. sensitized red cells to each tube.

(4) $30 \mathrm{~min}$. later, dispenser (B) adds $3.5 \mathrm{ml}$. saline to each tube.

(5) $2 \mathrm{~min}$. later the read-out transfer unit aspirates the contents of each tube into the absorptiometer, which measures the optical density at $660 \mathrm{~nm}$.

Tubes in which complete haemolysis has occurred give a low optical density at $660 \mathrm{~nm}$, only slightly greater than that of water. The height of the recorder peak is proportional to the amount of nonhaemolysed cells and a calibration curve may be run with each batch as follows:

Dilute $1.0 \mathrm{ml}$. sensitized red cells suspension with $3.0 \mathrm{ml}$. saline.

In four $3 \times 0.5$ in. test tubes place $0.2,0.4,0.6$, and 0.8 $\mathrm{ml}$. dilute red cells and add saline to give a final volume

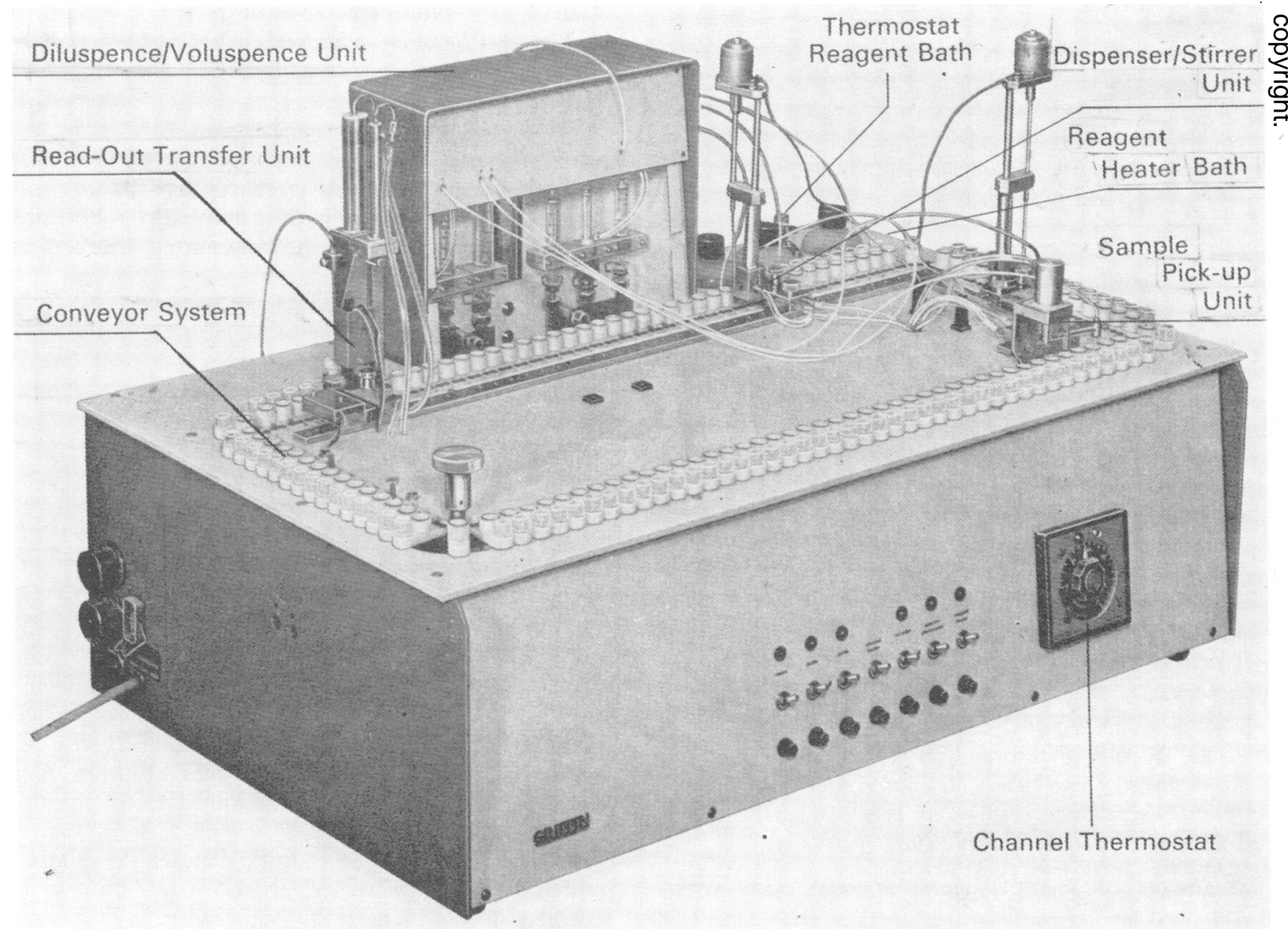

FIG. 1 General view of Bioanalyst 
of $0.8 \mathrm{ml}$. Place in carriers immediately before step (5). By a suitable arrangement of the actuating pins, it is possible to add antigen to alternate tubes, and by this means, a test for anticomplementary activity may be made. Alternatively positive sera may be re-run substituting saline for antigen.

\section{Results}

CRITERIA FOR READING RESULTS

By the manual method a specimen was marked positive if any free cells could be seen. By the automated method, sera were recorded as positive if there was less than 90 per cent. lysis. A typical section of the recorded results is shown in Fig. 2 where 90 per cent. lysis corresponds to 23 on the vertical scale. There was usually no difficulty in reading the results, but if a lower limit of lysis was set the number of positives fell sharply (Fig. 3). It was not possible to distinguish degrees of lysis greater than 90 per cent. Fig. 2 also shows that there was no carry over from strongly positive sera.

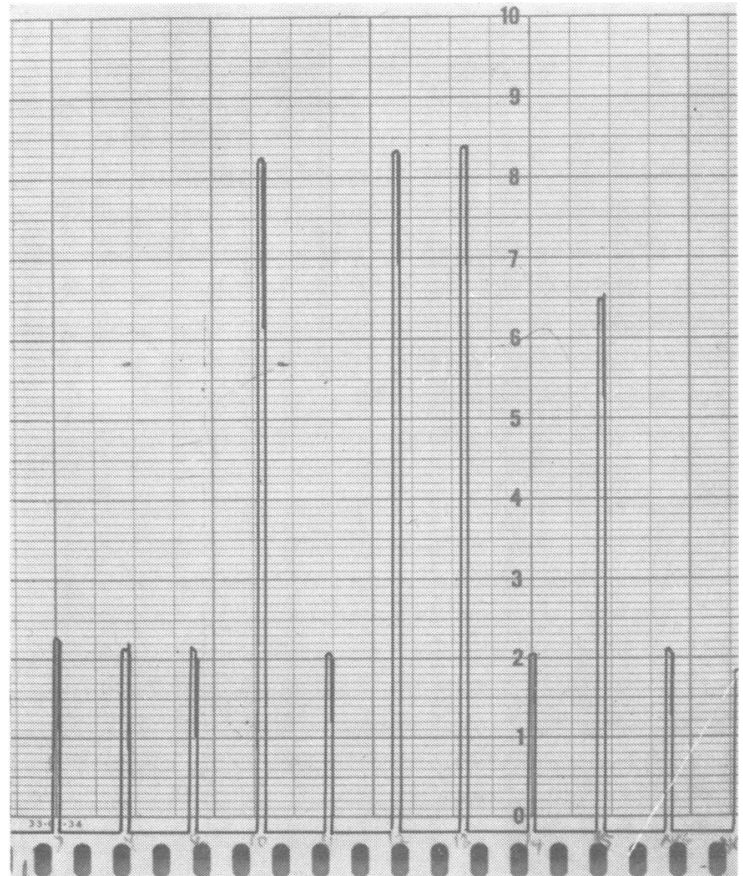

FIG. 2 Section of recorded results. Each deflection is the reading of one tube. Deflection upwards represents decreasing lysis, on an arbitary scale. 100 per cent. lysis $=23$. No lysis $=84$

COMPARISON OF RESULTS FROM MANUAL AND AUTOMATED TESTS

1,000 sera were tested manually and by the autonuted procedure. The total positive by both methods

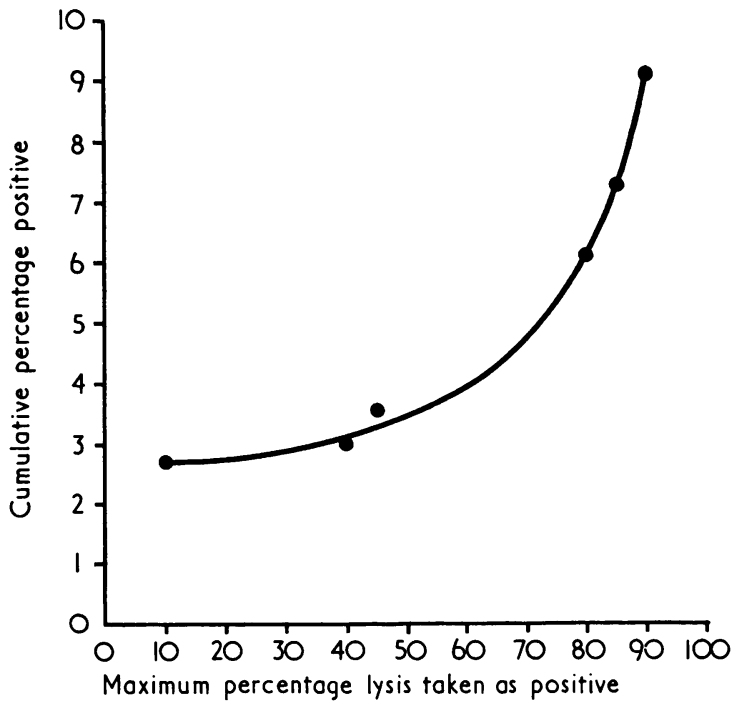

FIG. 3 Cumulative percentage frequency of positive results as a function of the maximum percentage lysis taken as positive, calculated from 311 tests of which 27 were positive

was 111 and the total negative by both methods 867 (Table). Five sera were positive by the automated method and negative manually. Seventeen sera were negative by the automated method and positive manually.

TABLE Comparison of WR results by manual (M) and automated $(A)$ methods

\begin{tabular}{|c|c|c|c|c|c|c|}
\hline \multicolumn{3}{|c|}{ Results } & \multirow{2}{*}{$\frac{M+A+}{\begin{array}{l}58 \\
53\end{array}}$} & \multirow{2}{*}{$\begin{array}{l}M-A- \\
\frac{140}{727}\end{array}$} & \multirow{2}{*}{ 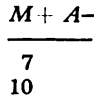 } & \multirow{2}{*}{$\frac{M-A+}{0}$} \\
\hline Sera & $\begin{array}{l}\text { Selected } \\
\text { Routine }\end{array}$ & $\begin{array}{l}205 \\
795\end{array}$ & & & & \\
\hline & Total & 1000 & 111 & 867 & 17 & 5 \\
\hline
\end{tabular}

The small number ( 0.5 per cent.) of 'false' positives by the automated method is acceptable, since these will be checked by other tests done in parallel. More serious is the 1.7 per cent. of 'false' negative results; these seventeen sera all showed only a weak positive result by the manual method, the discrepancy being due to the 5-fold dilution factor necessitated by the volume required to fill the flowthrough system.

A smaller colorimeter unit is under development which should require less than $1.0 \mathrm{ml}$. fluid with a corresponding increase in sensitivity. This modification should produce better correlation between the two methods. 


\section{Discussion}

The system detailed above makes possible the complete automation of the technique, including serum dilution, addition of reagents, and reading of results, of one of the most common investigations in clinical serology.

The sample rate of 120 per hour is considerably faster than that achieved by continuous flow methods and is accompanied by a marked economy in reagents.

The use of a calibration curve allows quantitation and standardization to be applied to a test which until now, at least in routine laboratories, has usually been based on subjective reading of results.

While one of the major advantages of discrete analysis is that manual techniques may be automated with virtually no modification, this particular system lends itself readily to alterations.

\section{Summary}

A method for carrying out the Wassermann complement-fixation test automatically, using a discrete analyser, the Bioanalyst, has been described. The results on 1,000 sera were compared with those given by the laboratory routine manual method done in parallel, 111 tests were positive and 867 negative by both methods, and the results were discordant in 22 tests of which five were 'false' positive and seventeen 'false' negative, taking the manual results as true.

Possible reasons for the discrepancies and ways of overcoming them are discussed. This method of automation appears to offer many advantages over the manual method.
We are indebted to Dr. A. Glynn for his helpful advice and criticism and to Mr. A. T. Williams for technical assistance in the course of the work.

We should also like to thank Prof. R. E. O. Williams for permission and encouragement to carry out this work in his department.

\section{References}

Pugh, V. W., and Gaze, R. W. T. (1966) f. clin. Path., 19, 595

TAYLOR, C. E. D. (1969) 'Serological techniques', in 'Automation and Data Processing in Pathology', ed. T. P. Whitehead, p. 14. F. clin. Path., Symposium Supplement No. 3. B.M.A., London

VARGUES, R. (1964) Technicon International Symposium, London

\section{Automation de l'épreuve de fixation du complément de Wassermann grâce à l'emploi d'un analyseur discontinu}

\section{SOMMAIRE}

On décrit une méthode pour effectuer automatiquement l'épreuve de fixation du complément de Wassermann pą un analyseur discontinu: le Bioanalyst. Les résultats sue 1.000 sérums furent comparés avec ceux de la méthode manuelle habituelle pratiquée en parallèle; 111 épreuves furent positives et 867 négatives avec les deux méthodes. Les résultats furent discordants dans 22 cas, avec 5 'faux' positifs et 17 'faux' négatifs si l'on en juge par les résultats de l'examen manuel.

On discute les raisons rossibles de ces divergences et les moyens de les corriger. Cette méthode d'automation semble offrir plusieurs avantages par rapport à la méthode manuelle. 